\title{
ESTADO DE LA CUESTIÓN
}

\section{SOBRE EL CANON LITERARIO}

Rosa María Aradra Sánchez (ed.) 



\title{
PRESENTACIÓN
}

\author{
Rosa María ARADRA SÁNCHEZ \\ Universidad Nacional de Educación a Distancia \\ rmaradra@flog.uned.es
}

Los debates y estudios sobre el canon literario han experimentado tal auge en los últimos años que ya es un lugar común comenzar cualquier aproximación a este tema resaltando el inusitado interés que ha provocado en distintos medios, sobre todo desde mediados de los noventa. Si algún otro mérito hubiera que añadirle al reeditado libro de Harold Bloom (1994), El canon occidental, sin duda uno de los más destacables sería el de haber despertado de su letargo infinidad de voces que desde diversos sectores, contextos y literaturas, se han pronunciado sobre el tema. Pero la cuestión de qué autores leer o qué obras imitar, qué convierte en clásico a un escritor, cuáles son los textos fundamentales de una literatura y por qué, data de los mismos orígenes de la reflexión literaria, y es constante, aunque con matices diferentes a lo largo de la historia. Los discursos sobre la literatura llevan en su propia esencia una tarea de valoración, selección, y, en consecuencia, también de exclusión, connatural al concepto mismo de literatura.

Sin embargo, es en este último período de cambio de siglo, en el que hablamos de postmodernidad, de globalización, de nuevos paradigmas cul- 
turales, cuando estas cuestiones alcanzan un mayor relieve, y así ha sucedido, sobre todo en el ámbito norteamericano, al que alude directamente Bloom.

El descentramiento y la multiplicación de los focos de definición y orientación de la cultura, señalados como una de las razones de tal efervescencia teórica (Gonzalo Navajas, 2006: 90), ha acentuado el contraste, precisamente entre los modos canónicos, que se asientan en el orden, la tradición y los valores heredados, y la globalización, la pluralidad, la movilidad y la apertura de los nuevos enfoques comunicativos, económicos, políticos, ideológicos y culturales. En la mente de todos están los efectos del postcolonialismo, de las minorías, de la escritura de género, de las relaciones entre literatura, cine y las demás artes, del multilingüismo y de las nacionalidades, de Internet y de los últimos avances electrónicos.

Sobre este último aspecto, la revolución que han supuesto las nuevas tecnologías en los modernos medios de comunicación amplía notablemente el horizonte literario y lo transforma. La letra impresa adquiere nuevos formatos y convive con lo visual, lo fragmentario y lo transitorio. Se trata de todo un desafío a lo canónico, en el que hablar de cibercultura o de hipertextos cuestiona, como resume Sánchez-Mesa (2004: 34), los conceptos tradicionales de autoría, lectura, propiedad intelectual, originalidad o creatividad artística. De ahí la necesidad de revisar el concepto tradicional de literatura, género literario, periodización o historia de la literatura, lo que lleva implícito también el del canon. Su objeto de estudio, más impreciso, relativo y dinámico, se abre a posibilidades textuales no consideradas con anterioridad, que ahora reclaman su lugar en el horizonte epistemológico. El libro, la letra impresa como principal vía de transmisión literaria, cuenta con la presencia creciente de las nuevas tecnologías, de otros canales electrónicos y virtuales que están recategorizando la figura del emisor, del receptor y de los demás elementos del circuito comunicativo.

En esta línea Fernando Cabo (2006) ha destacado recientemente el surgimiento de un «canon global» vinculado a los grandes grupos editoriales y multimediáticos. En el mundo de la hipercomunicatividad, de la abundancia de información y de la rapidez y fugacidad de los intercambios comunicativos resulta lógico cuestionarse el futuro del canon.

A pesar de ello no deja de ser curiosa la proliferación en los últimos años de saberes compendiados y selectivos que orientan sobre los conocimientos esenciales, los títulos imprescindibles que hay que conocer, los libros que 
uno ha de leer antes de morir... y tantas otras listas de referentes canónicos. Inmersos en esta vorágine informativa y comunicativa, reconocemos la paralela demanda de una guía para navegar por tantos mares de información, la necesaria seguridad que se reclama desde la enseñanza de un conjunto de autores y de textos de gran valor literario, que son los que conforman nuestra tradición cultural.

Así, la aceptación de la flexibilidad, de la permeabilidad, y por qué no, de la fugacidad de algunos cánones, lo que hace no es contradecir el concepto mismo de canon, que se basa precisamente en los parámetros de durabilidad y de permanencia, sino que lo amplía y enriquece. De ahí también la necesidad de hablar de cánones, en plural. Hoy más que nunca es impensable defender una idea autónoma de la literatura que no tenga en cuenta, como ya destacó hace unos años Jenaro Talens (1994: 139), que se trata de una realidad definida por un conjunto de prácticas: escritura, lectura, interpretación, difusión, enseñanza, etc., de una realidad polisistémica, en los términos defendidos por Even-Zohar.

En este escenario de cambios y de replanteamientos teóricos, a pesar de que se ha destacado que la cuestión del canon no ha alcanzado en el ámbito hispánico la virulencia de otros, como ha sucedido en el norteamericano, sí podemos decir que ha tenido un hondo calado, y es mucha y diversa la bibliografía que ha generado y continúa generando, tanto desde la teoría como desde la práctica.

Aunque no es nuestra intención ahora hacer un balance exhaustivo de las publicaciones que este tema ha suscitado en nuestro contexto académico, hemos de reconocer que, desde el punto de vista teórico, siguen siendo de obligada referencia compilaciones como las de Jaume Pont y Josep M. SalaValldaura, que en 1998 recogían las propuestas presentadas al Col.loqui Internacional «Cànon Literari: Ordre i Subversió» (Lleida, 1996), o la imprescindible de Enric Sullà (1998), cuyo enfoque del tema y útil recopilación bibliográfica nos acerca a los textos clave del debate internacional. Además de las aportaciones incluidas en estos dos libros, los diferentes artículos y trabajos que ha dedicado José M. ${ }^{a}$ Pozuelo a la teoría del canon (1995, 2000, entre otros) y los de otros muchos especialistas, constituyen una clara muestra del interés de estas cuestiones para la teoría literaria actual. Pensemos en el divulgado número que Ínsula dedicara al canon (1996), o en el más reciente de Iberoamericana (2006), por citar sólo dos ejemplos, más todas las monografías, artículos y estudios diversos que han tratado el tema de manera directa o tangencial. 
Un rápido vistazo por la literatura publicada sobre la cuestión refleja las repercusiones que tales inquietudes teóricas están teniendo en nuestro país, sobre todo desde un punto de vista práctico, con aplicaciones concretas a la historia de la literatura española. Su actualidad lo ha convertido en tema de congresos y simposios, que reflejan en muchos casos proyectos de investigación realizados o en curso de realización de distintas universidades. El monográfico La elaboración del canon en la literatura española del siglo XIX (Díaz larios, 2002), o En torno al canon (López Bueno, 2005), que recoge interesantes investigaciones sobre poesía del Siglo de Oro, son algunos de ellos.

Hay estudios canonizadores, descanonizadores, sobre el canon contemporáneo, el canon académico, el escolar, el de una época, de un género, de un autor, el personal..., lo que muestra la variedad de perspectivas desde las que se puede analizar, ampliar, aplicar o censurar, en tal medida que se puede hablar de una popularización y apertura semántica del término. Con respecto a esto no hace mucho llamaba la atención Enric Sullà (2007) sobre la variedad de definiciones de que ha sido objeto en las últimas décadas, y optaba por una idea de canon como «conjunt d'obres i d'autors que una col-lectivitat considera valuós».

En cualquier caso, asistimos a lo que podríamos llamar la institucionalización de los estudios sobre el canon, convertido en capítulo específico de recientes manuales de teoría literaria, presente en programas de asignaturas del ámbito de la Teoría de la Literatura y la Literatura Comparada, de Historia de la Literatura española, de Literatura Hispanoamericana..., en cursos de doctorado, programas de Máster, etc., que sería prolijo detallar ahora. Con independencia de los caminos que tome la teoría literaria en el futuro con respecto a este tema, estos datos confirman el lugar que tales estudios se han creado en el terreno académico e institucional contemporáneos.

En este contexto, la revista Signa quiere tomarle el pulso a la cuestión de la mano de especialistas que desde diversos planteamientos reflexionan sobre tan controvertida cuestión.

Genera Pulido Tirado parte de las consecuencias que la revisión del canon en las últimas décadas del siglo Xx está teniendo en América Latina. Las publicaciones más recientes sobre literatura colonial y la reivindicación de la cultura y literatura indígenas, son claros ejemplos de apertura de un canon formado desde la metrópoli, que excluía hasta no hace tanto muchas de estas manifestaciones. En este sentido, la recepción de Bloom en el ámbito latinoamericano ha potenciado la necesidad de repensar un canon eurocéntrico 
y de valorar unos textos de gran importancia en las sociedades en las que surgen, con lo que ello supone de reajuste en la visión tradicional de los géneros literarios al atender ahora a unas modalidades antes desdeñadas por los sectores académicos. El riesgo que se corre en este cuestionamiento del canon tradicional es caer en el extremo opuesto de la incorporación indiscriminada de géneros o autores marginados hasta el momento, por el hecho principal de su exclusión histórica.

De ahí la importancia de distinguir — siguiendo a Mignolo— el canon que responde a preguntas como qué debe enseñarse y por qué, y el canon que, visto desde una perspectiva epistemológica, se plantea cómo se forman y transforman los cánones o a qué grupos sociales representan. La cuestión de fondo es evitar la proyección de valores del «primer mundo» sobre literaturas del «tercer mundo», aplicar criterios de carácter universal a literaturas regionales y, viceversa, enseñar literaturas regionales como si fueran universales (Mignolo, 1998: 268). Por ello defiende una teoría que supere las fronteras lingüísticas y culturales.

En la misma línea, José María Pozuelo apuesta por un cambio en la orientación del problema. Más que plantear si existe un canon hispánico, considera fundamental la defensa de una unidad de la literatura escrita en español, transmisora de los valores que la hacen universal. En Estados Unidos los estudios culturales han favorecido una evidente falta de consenso sobre los textos que deben fundamentar los estudios literarios, poco válida, según este crítico, para trasladar al ámbito hispánico. Argumenta para ello la unidad de la cultura hispánica, en la que a la utilización de un mismo idioma se han de sumar otras razones que acentúan las continuas y marcadas influencias entre las letras españolas y las del continente americano. Premios, instituciones, asociaciones, actividad editorial, deudas literarias, estudios, exilios... fortalecen ese sentimiento por encima de identidades culturales particulares.

José Domínguez Caparrós se centra, desde la teoría, en aquellas corrientes o teóricos del siglo XX esenciales para el análisis literario de obras específicas, para el ejercicio de la crítica literaria y del enjuiciamiento de obras concretas. La noción de valor, esencial en todo proceso canónico, responde a unos presupuestos estéticos y teóricos que respaldan la aceptación o el rechazo de los textos, su selección. Inmanentismo, literariedad, connotación, expectativas del receptor, son conceptos que, de la mano del formalismo, la semiótica, la hermenéutica..., han alcanzado una solidez teórica consensuada a lo largo de la última centuria que los ha convertido en clásicos de la teoría. 
Por su parte, José Francisco Ruiz Casanova aborda la relación de las antologías con la constitución del canon poético, y repasa algunas obras panorámicas de poesía española del siglo XX atendiendo al modelo didáctico anglosajón de las teaching anthologies. Antología y pedagogía constituyen, junto a la historia de la literatura, tres de los pilares fundamentales de los procesos de canonización. Las antologías desempeñan una función didáctica, en tanto selección intencional de textos que aseguran la durabilidad de determinados valores y el conocimiento de generaciones futuras de los materiales que rescata el antólogo. No se trata de un viaje que empieza en el pasado y que acaba en el presente, sino que —como bien señaló Guillén (1985: 417) - lo orienta hacia el futuro. Desde esta perspectiva, su función, con independencia de que estén limitadas a una época o a una estética, es esencial en la formación y el gusto lector.

La literatura es una realidad polisistémica en la que se impone una mirada múltiple hacia diferentes aspectos, y lo mismo sucede con el canon. El trabajo de Manuel Asensi es, en esta línea, una documentada reflexión sobre la función performativa de la imaginación literaria y la conveniencia de tener en cuenta aspectos como la determinación geopolítica del sujeto y su pluralidad. Partiendo del debate contemporáneo sobre la subalternidad, nos ofrece su lectura de una de las obras canónicas del Siglo de Oro, el Lazarillo de Tormes, como ilustración de cómo usamos e interpretamos los textos canónicos.

Por último, mi aportación ofrece un repaso por algunos de los elementos más relevantes en la formación del canon literario de los siglos XVIII y XIX, un amplio período, marcado por profundas transformaciones conceptuales e institucionales. En este proceso, aparte de los tradicionales manuales de retórica y poética o preceptivas literarias, de las antologías y de las historias de la literatura, otros medios influyen en la constitución de los cánones literarios: la prensa periódica, las traducciones, las repercusiones editoriales y los planes de estudio, que van dibujando el complejo mapa de la recepción y difusión literarias.

En definitiva, distintas propuestas que no agotan, sino que invitan a una reflexión sobre el canon desde flancos distintos, pero complementarios, con el deseo común de entender un poco mejor el arte de la palabra. 


\section{REFERENCIAS BIBLIOGRÁFICAS}

AA.VV. (1996). «Un viaje de ida y vuelta. El canon». Ínsula 600.

BLOOM, H. (1994). El canon occidental. Barcelona: Anagrama, 1995.

CABO ASEGUINOLAZA, F. (2006). Manual de teoría de la literatura. Madrid: Castalia.

DÍAZ LARIOS, L. F. (et al.) (2002). La elaboración del canon en la literatura española del siglo XIX. Barcelona: Universitat.

GUILLÉN, C. (1985). Entre lo uno y lo diverso. Introducción a la literatura comparada. Barcelona: Crítica.

LÓPEZ BUENO, B. (ed.) (2005). En torno al canon: aproximaciones y estrategias. Sevilla: Universidad de Sevilla.

LÓPEZ DE ABIADA, J. M. y PÉREZ CINO, W. (coords.) (2006). «Dossier: Pensar el canon. Teoría y ejercicio crítico». Iberoamericana VI. 22, 81158.

MIGNOLO, W. (1998). «Los cánones y (más allá de) las fronteras culturales (o ¿de quién es el canon del que hablamos?). En El canon literario, E. Sullá (ed.), 237-270. Madrid: Arco / Libros.

NAVAJAS, G. (2006). «El canon y los nuevos paradigmas culturales». Iberoamericana VI. 22, 87-97.

PONT, J. y SALA-VALLDAURA, J. M. (1998). (eds.) Cànon literari: ordre i subversió. Lleida: Institut d'Estudis Ilerdencs.

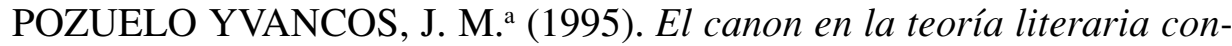
temporánea. Valencia: Ediciones Episteme.

- y ARADRA SÁNCHEZ, R. M. (2000). Teoría del canon y literatura española. Madrid: Cátedra.

SÁNCHEZ-MESA, D. (ed.) (2004). Literatura y cibercultura. Madrid: Arco / Libros.

SULLÀ, E. (ed.) (1998). El canon literario. Madrid: Arco / Libros.

- (2007). «El cànon literari: cap a una definició operativa». Literatures 5, 9-22.

TALENS, J. (1994). «El lugar de la Teoría de la literatura en la era del lenguaje electrónico». En Curso de Teoría de la Literatura, D. Villanueva (coord.), 129-143. Madrid: Taurus. 